\title{
Incessant form of a benign arrhythmia in a patient with a DDD pacemaker.
}

\author{
Karol Kołakowski, ${ }^{1, \mathrm{~B}-\mathrm{F}}$, Aleksander Maciąg, ${ }^{1, \mathrm{~A}-\mathrm{C}, \mathrm{E}-\mathrm{F}}$, Michał M Farkowski ${ }^{1, \mathrm{~B}-\mathrm{C}, \mathrm{E}-\mathrm{F}}$, Mariusz Pytkowski ${ }^{1, \mathrm{~B}-\mathrm{C}, \mathrm{E}-\mathrm{F}}$, \\ Hanna Szwed ${ }^{1, C, E-F}$ \\ A - Research concept and design, B - Collection and/or assembly of data, C - Data analysis and interpretation, \\ D - Writing the article, E - Critical revision of the article, F - Final approval of article
}

1 2nd Department of Coronary Artery Disease Institute of Cardiology

Address for correspondence:

Karol Kołakowski, 2nd Department of Coronary Artery Disease Institute of Cardiology email: kkolakowski@ikard.pl

\begin{abstract}
Aleksander Maciąg, 2nd Department of Coronary Artery Disease Institute of Cardiology email: amaciag@ikard.pl
\end{abstract}

Michał M Farkowski, 2nd Department of Coronary Artery Disease Institute of Cardiology email: mfarkowski@gmail.com

Mariusz Pytkowski, 2nd Department of Coronary Artery Disease Institute of Cardiology email: mpytkowski@ikard.pl

\begin{abstract}
Hanna Szwed, 2nd Department of Coronary Artery Disease Institute of Cardiology
email: hszwed@ikard.pl
\end{abstract}

Received: 29.12.2016

Revised: 31.12.2016

Accepted: 31.12.2016

\section{Key words:}

\section{atrioventricular nodal re-entrant tachycardia, radiofrequency ablation, incessant AVNRT}

\section{Introduction:}

Paroxysmal atrioventricular nodal re-entrant tachycardia (AVNRT) is a common supraventricular tachycardia (SVT) which impairs patients' quality of life $\mathrm{f}^{[1,2]}$. Usually it is self-limiting, but it may be successfully terminated with vagal manoeuvres or pharmacological agents. An incessant form of AVNRT, while rare, can be dangerous due to the risk of tachycardiomyopathy and debilitating symptoms, which obliges the clinician to consider early radiofrequency ablation (RFA) as the treatment of choice.

\section{Methods and Results:}

We present the case of an 83-year-old man with a history of paroxysmal atrial fibrillation, hypothyroidism, and type 2 diabetes mellitus, with a dual chamber pacemaker implanted 4 years ago due to tachycardia-bradycardia syndrome, who presented at the Emergency Department with severe heart palpitations, chest discomfort and accompanying dizziness. The symptoms had lasted for the past 4 days and were severely debilitating. The patient had a history of infrequent SVT episodes, but no definite diagnosis had ever been established. Surface electrocardiogram (Fig. 1) revealed narrow QRS tach-

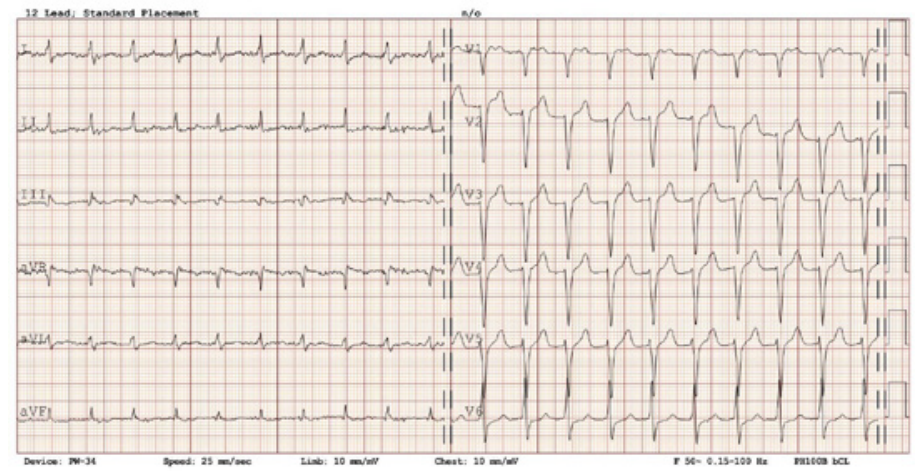

Figure 1 ECG showing tachycardia with short RP and $r^{\prime}$ wave in V1

ycardia with a heart rate of 120/min and an $\mathrm{r}^{\prime}$ wave in V1. In the "ad hoc" pacemaker interrogation (Fig. 2) retrograde atrial depolarization was confirmed, therefore making AVNRT the most possible diagnosis. After failed attempts of termination of SVT by vagal manoeuvres, anti-tachycardia pacing was performed with successful conversion to sinus rhythm 58/ min. Unfortunately, after 30 minutes the arrhythmia recurred and the patient was admitted to hospital to plan a further treatment strategy. 


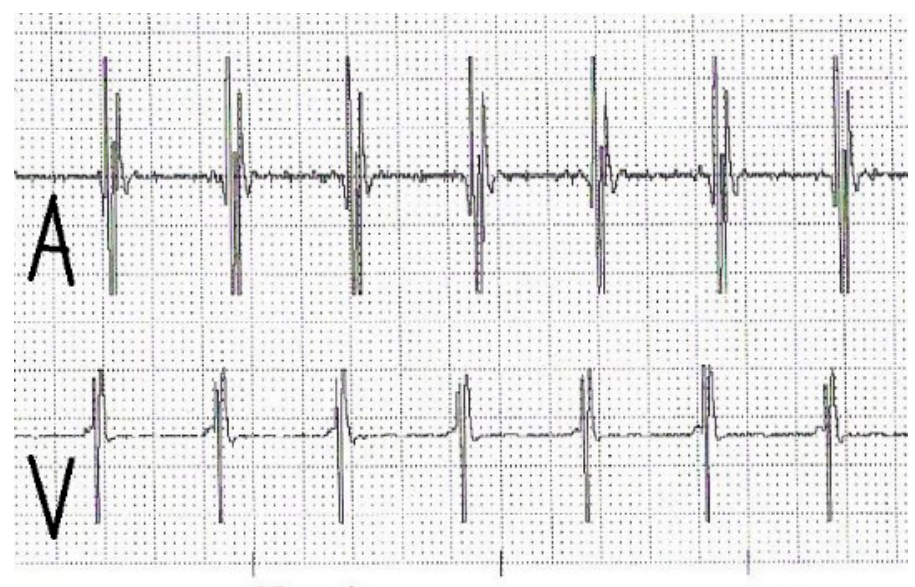

Figure $2 \mathrm{~A}$ strip from the pacemaker interrogation showing retrograde atrial depolarization

During the next three days of hospitalization propafenone and metoprolol were administered intravenously and verapamil orally with only short periods of sinus rhythm. Due to resistance to medical therapy the patient was scheduled for emergency RFA. During the procedure, the initial diagnosis of AVNRT was confirmed and the slow pathway conduction was eliminated, rendering the arrhythmia non-inducible. After a few days of post-ablation observation, no recurrence of the arrhythmia had been observed and the patient was discharged. The first follow-up visit was scheduled three months after the RFA with no clinical signs of arrhythmia and no SVT episodes on device interrogation. Further ambulatory follow-up was planned according to the standard clinical guidelines concerning patients with pacemakers.

\section{Discussion:}

Atrioventricular nodal re-entrant tachycardia is usually a benign form of SVT with sudden onset and termination, susceptible to pharmacological treatment. It is extremely rare to observe such resistance to standard, non-invasive therapy ${ }^{[3,4]}$. Usually an incessant form of SVT is observed due to focal atrial tachycardia or permanent junctional reciprocating tachycardia, both of which were ruled out during the invasive electrophysiological study. In the present case the incessant character of the arrhythmia is most likely due to age-related slowdown of impulse propagation in the AV node. In order to prevent tachycardiomyopathy and to avoid reduced health-related quality of life, it was decided to perform early RFA.

\section{Conclusion:}

To conclude, RFA should always be considered as a treatment of choice in incessant AVNRT. Intracardiac electrogram may help establish the diagnosis of AVNRT.

\section{References}

1. Katritsis DG, Boriani G, Cosio FG, et al. European Heart Rhythm Association (EHRA) consensus document on the management of supraventricular arrhythmias, endorsed by Heart Rhythm Society (HRS), Asia-Pacific Heart Rhythm Society (APHRS), and Sociedad Latinoamericana de Estimulación Cardiaca y Electrofisiologia (SOLAECE). Europace. 2016 Nov 17 [Epub ahead of print] doi:10.1093/europace/euw301

2. Kułakowski P, Piotrowski R, Stec SM, et al. Ablation of atrioventricular nodal reentrant tachycardia: predictors of long-term success. Kardiol Pol. 2013;71(9):903-10. doi: 10.5603/KP.2013.0224.

3. Jastrzębski M, Pitak M, Rudziński A, Czarnecka D. Pseudo-PJRT in an 8 year-old boy with severe decompensated heart failure and recurrent episodes of ventricular fibrillation. Kardiol Pol. 2013;71(3):310-4. doi: 10.5603/KP.2013.0050.

4. Maury P, Detis N, Duparc A, Mondoly P, Rollin A, Delay $\mathrm{M}$. Incessant atrio-ventricular node reentrant tachycardia induced by unapparent dual atrio-ventricular node conduction. Pacing Clin Electrophysiol. 2013 Apr;36(4):e103-6. doi: 10.1111/j.1540-8159.2012.03412.x. 